\title{
Case Report 46
}

William Martel, M.D.*, and M.R. Abell, M.D.

Departments of Radiology and Pathology, University of Michigan Medical Center, Ann Arbor, Michigan, USA
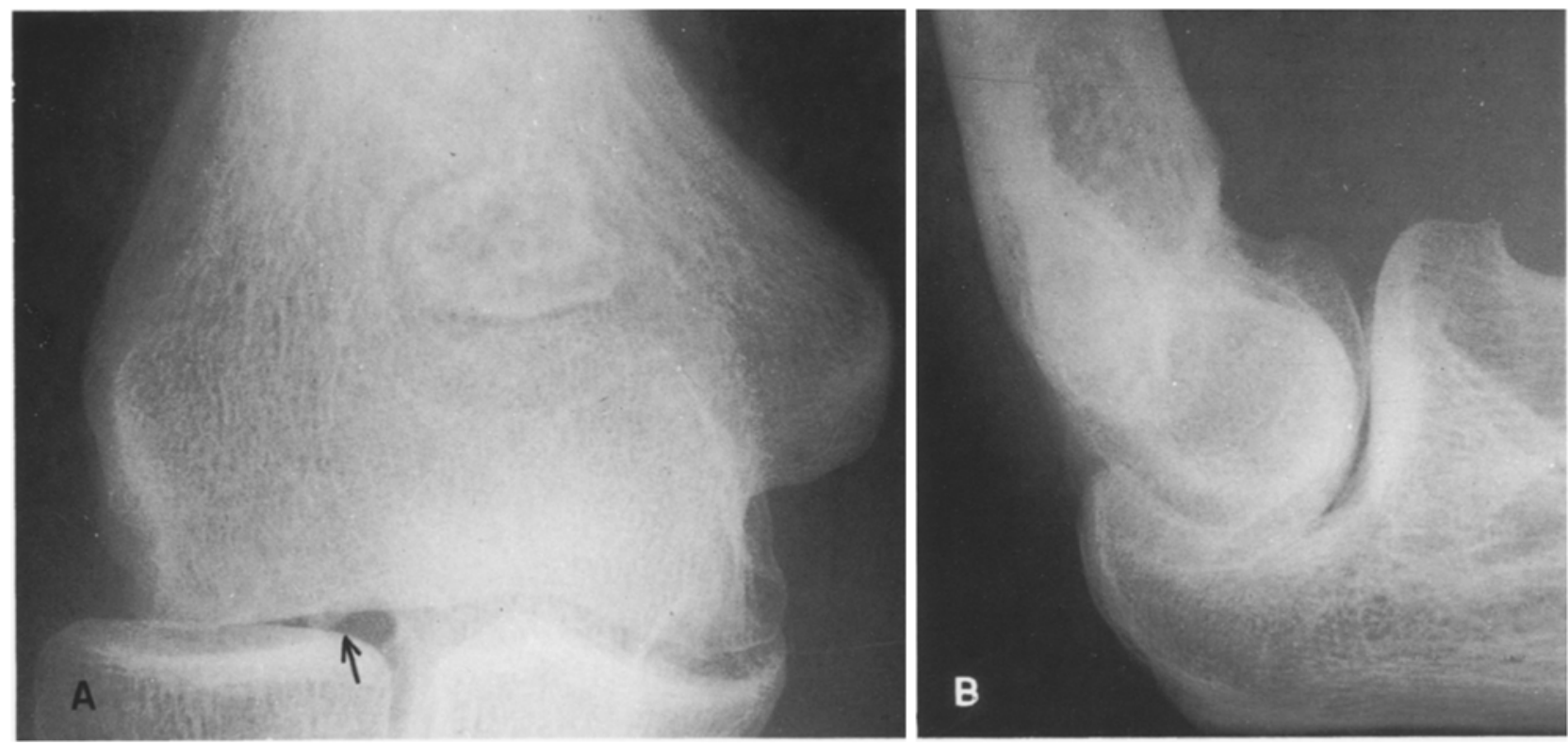

Figs. $1 \mathrm{~A}$ and B. Anteroposterior and lateral films of the right elbow show a large, irregular, calcified, bony mass in the supratrochlear fossa and a much smaller dense fragment lying just above the radial head in the frontal plane film (arrow). The margin of the capitulum is somewhat irregular and sclerotic, with a coarsened trabecular pattern

\section{History}

This 35-year-old man presented with a history of intermittent pain and swelling of the right elbow. He dated the onset of symptoms to an injury experienced

\footnotetext{
* Presented by Dr. William Martel at the 3rd Annual Meeting of the International Skeletal Society in Montreal, Canada, September 10 th-12th 1976

Address reprint requests to: W. Martel, M.D., Department of Radiology, University of Michigan Medical Center, Ann Arbor, MI 48104, USA
}

at the age of 11 years, at which time swelling and limitation of motion persisted for several weeks after the injury. Pain had continued intermittently through the years, but his symptoms increased in severity just before admission, presumably in association with the patient's occupation, which required him to lift heavy weights.

Physical examination of the elbow showed a normal range of motion, with no tenderness or crepitus.

Surgical exploration of the elbow was performed. 


\section{Histological Sections}

A freely mobile osteocarilaginious loose body lying in the supratrochlear fossa was removed (see below).
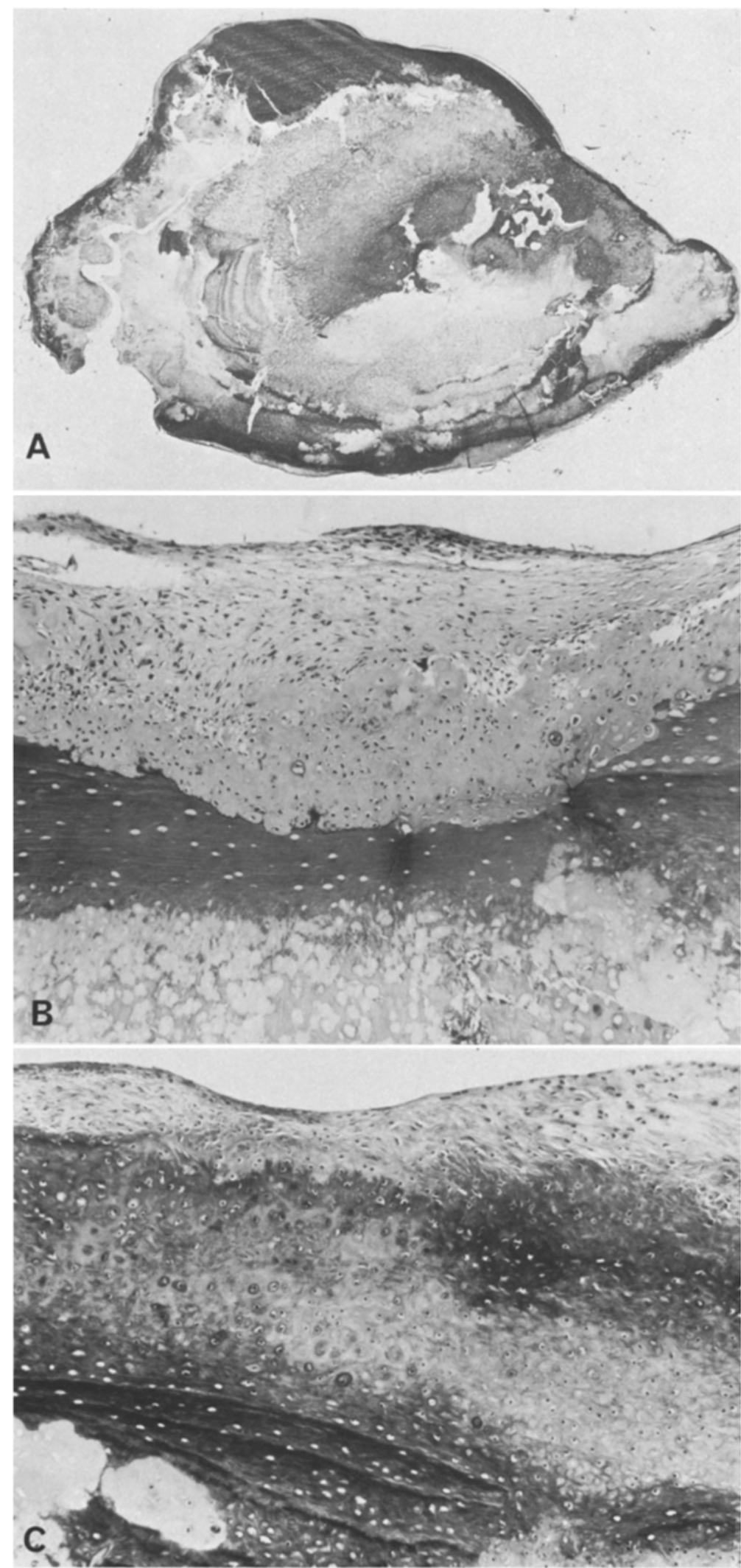

Fig. 2A. A photomicrograph of a histological section ( $\mathrm{H}$ and $\mathrm{E}$ stain $\mathrm{X} 7$ ) of this loose body shows a central mass of necrotic cartilage and a lesser amount of necrotic bone, surrounded by newly formed bone (dark areas) and proliferating nodules of cartilage (light areas)

Fig. 2B. In this photomicrograph of another histological section from the same loose body $(\mathrm{H}$ and $E$ stain $X 126$ ) a synovial-appearing membrane is observed on the surface, beneath which are proliferating cartilage, necrotic bone (dark) and necrotic cartilage (light)

Fig. 2C. In the photomicrograph ( $\mathrm{H}$ and $\mathrm{E}$ stain $X$ 126) proliferating cartilage with focal osseous metaplasia is observed beneath a synovial appearing membrane 


\section{Diagnosis: Post-TraumaticNecrosis ("Osteochondritis Dissecans") Supratrochlear Fossa Distal End of Humerus}

The differential diagnosis includes an accessory ossicle in the area of the supratrochlear fossa ("sesamum cubiti"), an accessory ossicle within the triceps tendon posterior to the elbow joint ("patella cubiti"), and a large calcified nidus in an osteoid osteoma or osteoblastoma.

\section{Discussion}

Surgical exploration of the right elbow via a posterior approach showed a freely mobile osteocartilaginous body measuring approximately $10 \times 15 \times 15 \mathrm{~cm}$ in the supratrochlear fossa. No other loose bodies were observed. The loose body was roughly pyramidal in shape and consisted of a central mass of necrotic articular cartilage and cancellous bone in which only the structural outlines were discernible. An irregular nodular zone of proliferating cartilage and newly formed bone surrounded most of the necrotic nidus of the loose body which was removed. The cartilage and bone were capped by a patchy layer of young fibroblasts with a surface covering of slightly plumper cells resembling synovial endothelium. No evidence of inflammation or neoplasm was identified.

The case raises the question of the origin of the necrotic osteocartilaginous fragment. Similar cases have been termed in the past "osteochondritis dissecans of the supratrochlear septum". This structure constitutes the floor of the supratrochlear fossa, consisting of a thin sheet of bone which separates the coronoid and olecranon fossae. A foramen, often bilateral and symmetrical, may be observed within the septum. The suggestion has been offered that trauma may produce ischemic necrosis of the septum, generating one or more osteocartilaginous fragments which may lie within the supratrochlear fossa. Published roentgenograms of such cases resemble those in the present case. No tenable explanation has been offered as to why ischemic bone, removed from articular cartilage, should acquire a cartilaginous component. The issue is further complicated by reference to an inconstant accessory bone in the supratrochlear fossa ("supratrochlear foraminal bone"), which presumably may undergo traumatic necrosis. It is postulated in this present case and possibly in others that a loose fragment identified radiologically and surgically arose from the articular surface and migrated to the supratrochlear fossa, being analogous to cases previously designated as "osteochondritis dissecans of the supratrochlear septum".

The discrepancy between the size of the fragment in this case and the defect in the capitulum is easily explained. Hyperplasia of the cartilage may occur because the latter receives its nourishment from synovial fluid. Furthermore, in some cases, osteogenesis may contribute to the size of the fragment, particularly if the latter derives a blood supply by attaching to a synovial membrane. In addition, the original defect in the subchondral bone may diminish as a result of reparative bone formation. The foramen in the supratrochlear septum should not be misconstrued as a site of the loose fragment, inasmuch as such foramina occur in clinically normal elbows in which no loose bodies appear.

In the present case the radiological appearance of the capitulum and the operative and histological findings tend to support the interpretation that the loose body in the supratrochlear fossa was avulsed from the area of the capitulum. It is of interest that this patient developed similar symptoms in the other (left) elbow two years later. A loose body approximately $3 \mathrm{mms}$ in diameter, unrelated to the supratrochlear fossa, was identified radiologically in the left elbow and its presence confirmed surgically and pathologically. An irregular defect in the capitulum, presumed to be the site of origin of the loose body, was noted. Here, too, the radiological diagnosis of post-traumatic necrosis ("osteochondritis dissecans") of the left elbow was established both surgically and pathologically.

In considering the differential diagnosis, the major source of confusion lies in the exclusion of a congenital anomaly. As alluded to in the foregoing, Pfitzner (prior to discovery of the roentgen ray) described an inconstant ossicle lying posterior to and near the supratrochlear fossa of the elbow which he termed "sesasum cubiti". No anatomical configuration since then of such an accessory bone has been described. Published cases, however, of "osteochondritis dissecans" have included roentgenograms in which the osteocartilaginous fragment simulates such an ossicle. In addition, the entity of post-traumatic necrosis ("osteochondritis dissecans") of the elbow joint must be distinguished from "patella cubiti", a rare condition consisting of an ossicle within the triceps tendon posterior to the joint. It has not been determined whether the presence of such a fragment is of traumatic or of developmental origin.

And finally, cases have been observed of a large calcified nidus of an osteoid osteoma (or osteoblastoma) lying within the supratrochlear fossa. Such a 
lesion usually is easily distinguished radiologically from an osteocartilaginous loose body because its indistinct, "smudge-like" appearance contrasts with the sharply defined margins of an osteocartilaginous fragment as noted in this case.

\section{References}

1. Burman, M.D.: Unusual locking of the elbow joint by the sesamum cubiti and a free joint body. Am. J. Roentgenol. Radium Ther. Nucl. Med. 45, 731 (1941)
2. Ahlgren, S., Rydholm, A.: Patella cubiti. Report of an operated case. Acta Orthop. Scand. 45, 931 (1975)

3. Snarr, J.W., Abell, M.R., Martel, W.: Lymphofollicular synoyitis with osteoid osteoma. Radiology 106, 557 (1973)

4. Crysler, W.E., Morton, H.S.: Osteochondritis dissecans of the supra-trochlear septum of the humerus. Am. J. Roentgenol. Radium Ther. Nucl. Med. 54, 41 (1945)

5. Lerner, H.H., Watkins, M.B., Resnick, B.: Osteochondritis Dissecans of the supratrochlear septum of the humerus. Am. J. Roentgenol. Radium Ther. Nucl. Med. 55, 717 (1946)

6. Keats, T.E.: An Atlas of Normal Roentgen Variants that May Simulate Disease, pp. 124-143. Chicago: Year Book Medical Publishers 1973 